\title{
Cryptotanshinone Induces Apoptosis of HL-60 Cells via Mitochondrial Pathway
}

\author{
Wanmao Ni, Wenbin Qian and Xiangmin Tong \\ Institute of Hematology, the First Affiliated Hospital, College of Medicine, Zhejiang University, 79\# Qingchun Road, Hangzhou \\ 310003, P. R. China \\ ${ }^{*}$ For correspondence: Email: niwanmao@gmail.com
}

Received: 26 February 2013

Revised accepted: 12 February 2014

\begin{abstract}
Purpose: To test the effect of Cryptotanshinone (CPT), a natural compound isolated from the plant Salvia miltiorrhiza Bunge, on human leukemic cell lines (HL-60).

Methods: HL-60 cells were treated with CPT. Cell growth inhibition (\%) was quantitated using MTT assay. Apoptosis detection with Annexin V-FITC/propidium iodide staining was followed by flow cytometry. Caspase-3, caspase-8, and caspase-9 colorimetric assay kit was used to determine caspase protease activity. Loss of mitochondrial membrane potential was examined by flow cytometry with JC-1 staining. Bax, PARP, p53, p21 and cytochrome $C$ were determined using Western blot.

Results: Morphologic assessment, Annexin V-FITC/propidium iodide staining results and sub-G1 percentage indicate that the cytotoxic effect of CPT was mediated by induction of apoptosis. Furthermore, increased Bax expression, decreased Bcl-2 expression, loss of mitochondria membrane potential (MMP), release of cytochrome $C$, activation of caspase enzyme, cleavage of PARP and accumulation of $p 53$ and p21 were detected during the apoptotic process. Caspase inhibitor partially abrogated CPT-induced apoptosis.

Conclusion: The results show that CPT induced apoptosis of HL-60 cell lines by mitochondria pathway, and suggest that CPT may serve as a potential therapy for leukemia.
\end{abstract}

Keywords: Cryptotanshinone, Salvia miltiorrhiza Bunge, Caspase, Membrane potential, Mitochondrial, Apoptosis, Leukemia, Cytochrome C, Cell cycle

Tropical Journal of Pharmaceutical Research is indexed by Science Citation Index (SciSearch), Scopus, International Pharmaceutical Abstract, Chemical Abstracts, Embase, Index Copernicus, EBSCO, African Index Medicus, JournalSeek, Journal Citation Reports/Science Edition, Directory of Open Access Journals (DOAJ), African Journal Online, Bioline International, Open-J-Gate and Pharmacy Abstracts

\section{INTRODUCTION}

Acute myeloid leukemia (AML) is a clonal hematologic disease characterized by uncontrolled proliferation and abnormal survival of immature myeloid progenitors [1]. Leukemia cells are unable to undergo growth arrest, terminal differentiation, and apoptosis in response to appropriate stimulation [2]. The standard therapeutic approach to AML is chemotherapy, either via monotherapy or combination treatment with drugs such as anthracycline, doxorubicin, or idarubicin. However, the prognosis of AML remains unsatisfactory.

Moreover,

standard chemotherapy is highly toxic and poorly tolerated [3]. Thus, it is necessary to develop novel therapeutic agents to improve the cure rate in AML.

The medicinal herb Danshen (Salvia miltiorrhiza Bunge) has been widely used in traditional Chinese medicine treatment for over 1,000 years. Cryptotanshinone (CPT) is a major constituent of tanshinones, which are extracted from Danshen, and has well-documented antioxidative and anti-inflammatory effects [4]. In addition, recent studies have shown that CPT 
could induce apoptosis in several kinds of solid tumor [5-7], which makes it a potential anticancer agent. However, there is a paucity of research on the effect of CPT on leukemia.

In this study, we have examined the effects of CPT on HL-60, a human leukemia cell line, and studied the mechanisms involved.

\section{EXPERIMENTAL}

\section{Chemicals and reagents}

Cryptotanshinone was purchased from LKT Laboratories (St. Paul, MN, USA). The purity was verified by high performance liquid chromatography. CPT was dissolved in DMSO and stored at $-20^{\circ} \mathrm{C}$. An Annexin V-FITC/PI Apoptosis Kit was purchased from Biosource (CA, USA). 5, ', 6,6'-Tetrachloro-1, 1',3,3'tetraethylbenzimidazolyl-carbocyanine iodide (JC-1) was purchased from Molecular Probes Incorporated (Eugene, OR, USA). Hoechst 33342 was purchased from Invitrogen (CA, USA). Caspase- $3,-8$, and -9 protease activity was determined by a Biovision kit (CA, USA), a pan-caspase inhibitor (Z-VAD-FMK). Specific caspase inhibitors for caspase-3 (Z-DEVD-FMK) and -9 (Z-LEHD-FMK) were purchased from Calbiochem (Merck, CA, USA). Antibodies Bax and $\mathrm{Bcl}-2$ were purchased from Santa Cruz Biotechnology Inc (CA, USA).

\section{Cell line and culture}

The HL-60 (human acute promyelocytic leukemia) cell line was purchased from American Type Culture Collection (Rockville, MD, USA). The cells were maintained in RPMI-1640 medium (Gibco, USA) containing 10\% fetal bovine serum (Gibco, USA) and 1\% penicillin-streptomycin (Gibco, USA) at $37^{\circ} \mathrm{C}$ in a humidified atmosphere of $5 \% \mathrm{CO}_{2}$.

\section{Growth inhibition assay}

The effect of CPT on cell growth inhibition was measured by a MTT assay based on the enzymatic reduction of 3-(4,5-dimethylthiazol-2yl)-2,5-diphenyl tetrazolium bromide (Sigma, MO, USA) to form formazan crystals. Cells $\left(10^{4} /\right.$ well) were grown on a 96-well microliter plate and incubated with or without CPT $(0-20 \mu \mathrm{g} / \mathrm{ml})$ in RPMI-1640/10\% fetal bovine serum. After $48 \mathrm{~h}$, $30 \mu \mathrm{l}$ MTT solution ( $5 \mathrm{mg} / \mathrm{ml} \mathrm{PBS}$ ) was added to each well and incubation was continued for 4 additional hours. Cell growth inhibition (\%) was calculated by measuring mass spectrometric absorbance at $540 \mathrm{~nm}$.

\section{Analysis of morphological changes}

After treatment, $\mathrm{HL}-60$ cells were washed with PBS, fixed with $70 \%$ ethanol, and stained with Hoechst 33342. Morphological changes were analyzed with fluorescence microscope.

\section{Flow cytometric analysis of apoptosis}

HL-60 cells $\left(1 \times 10^{6}\right.$ cells /well) were cultured in a 6 -well plate in the absence or presence of CPT for $24 \mathrm{~h}$. After washing the cells twice with cold PBS, cell pellets were resuspended in $100 \mu$ of labeling solution containing Annexin V-FITC and $\mathrm{PI}$, followed by $15 \mathrm{~min}$ incubation in the dark at room temperature. Apoptotic cells were detected by a FACS Calibur flow cytometer (Becton Dickinson).

\section{Cell cycle analysis}

After treatment with CPT for $24 \mathrm{~h}$, cells were briefly washed with PBS and harvested. Cell pellets were stained with $1 \mathrm{ml}$ DNA staining solution $(20 \mu \mathrm{g} / \mathrm{ml}$ of $\mathrm{Pl}$ and $100 \mu \mathrm{g} / \mathrm{ml}$ of RNaseA in PBS) in the dark at $37^{\circ} \mathrm{C}$ for 30 min. Percentages of cells within each phase of the cell cycle (G0-G1, S, G2-M) were determined by flow cytometry.

\section{Caspase activity assay}

Caspase protease activity was determined by caspase-3, caspase-8, and caspase-9 Colorimetric Assay Kit (Biovision, San Francisco, USA). Treated cells were re-suspended in lysis buffer, incubated on ice, centrifuged, received reaction buffer and specific caspase protease substrate, incubated at $37^{\circ} \mathrm{C}$ for $1-2 \mathrm{~h}$, then analyzed at $405 \mathrm{~nm}$ in a microplate reader (Model 680, BioRad).

\section{Mitochondrial membrane potential assay}

CPT-treated cells were harvested with PBS washing and re-suspended in $1 \mathrm{ml}$ PBS containing $10 \mu \mathrm{M} \mathrm{JC}-1$ staining dye at $37^{\circ} \mathrm{C}$ for $15 \mathrm{~min}$. After centrifuging, cell pellets were resuspended in $1 \mathrm{ml}$ PBS and analyzed by flow cytometry.

\section{Western blot analysis}

Control and CPT-treated HL-60 cells were collected and lysed at indicated times with lysis buffer containing $0.1 \mathrm{~mol} / \mathrm{L}$ EDTA, $0.05 \mathrm{~mol} / \mathrm{L}$ EGTA, $2 \mathrm{~mol} / \mathrm{L} \mathrm{NaCl}, 1 \mathrm{~mol} / \mathrm{L}$ Tris-HCl, $\mathrm{pH} 6.8$, $0.5 \% \mathrm{NP}-40$ and $10 \mathrm{mmol} / \mathrm{L}$ PMSF. Protein concentration was measured by Bradford method. Cell lysates containing $50 \mu \mathrm{g}$ of total 
cellular protein were fractionated in $12.5 \%$ SDSpolyacrylamide gels. Separated proteins were transferred to a polyvinylidene fluoride (PVDF) membrane (Millipore, USA) and incubated with primary antibodies, then visualized with horseradish peroxidase-conjugated secondary antibody (Santa Cruz, CA, USA). Primary antibodies used and their dilution ratios were: p53 (1:2000), p21 (1:500), Bax (1:1000), poly (adenosine diphosphate-ribose) polymerase (PARP) (1:2000), cytochrome C (1:1000), and GAPDH (1:5000). All these primary antibodies were purchased from Santa Cruz.

\section{Statistical analysis}

All data are expressed as the mean \pm standard deviation (SD). One-way analysis of variance (ANOVA) was performed to determine if any difference existed between groups. All analyses were performed by Graphpad Prism 5. $p<0.05$ was considered to be statistically significant.

\section{RESULTS}

The CPT inhibited HL-60 cell growth and induced morphological changes

CPT showed significant growth inhibition on $\mathrm{HL}$ 60 cells in a dose-dependent $(p<0.0001)$ and time-dependent manner $(p<0.0001)$ by MTT assay (Figure 1).

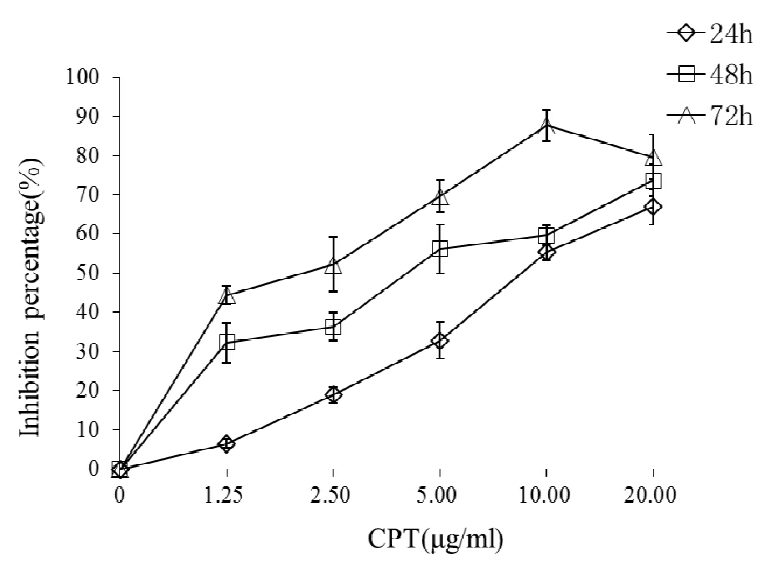

Figure 1: Time-dependent and dose-dependent growth inhibition of HL-60 cells treated with CPT (0 $20 \mu \mathrm{g} / \mathrm{ml}$ ). Each point represents the mean of data from 3 independent experiments

HL-60 cells treated with CPT $(5 \mu \mathrm{g} / \mathrm{ml})$ for $24 \mathrm{~h}$ triggered morphological changes such as cell shrinkage, nuclear condensation, and chromatin fragmentation, suggesting that CPT induced HL60 cell apoptosis (Figure 2).

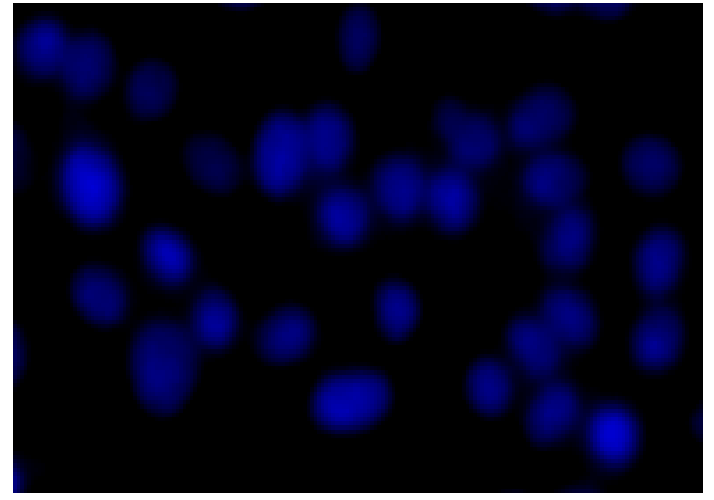

Control

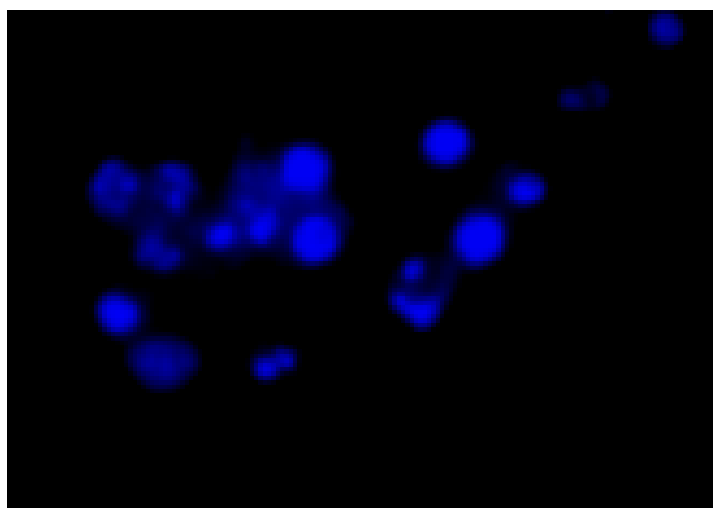

CPT

Figure 2: Effect of CPT on HL-60 morphology. HL-60 cells were treated with or without CPT $(5 \mu \mathrm{g} / \mathrm{ml})$ for 24 hours. Hoechst 33342 stained cells were analyzed by fluorescent microscopy

\section{CPT-induced apoptosis in HL-60 cells}

In addition to apoptosis in morphology as mentioned above, Annexin V/PI staining assay demonstrated that the apoptosis percentage of HL-60 cells increased in a dose-dependent manner $(p<0.01)$ after treatment with CPT for 24 hours, reaching 13.76 and $22.48 \%$ at CPT concentrations of 2.5 and $5 \mu \mathrm{g} / \mathrm{ml}$, respectively (Figure 3).

\section{CPT induced G0/G1 phase arrest and apoptosis of HL-60 cells}

Compared to untreated cells, HL-60 cells treated with $5 \mu \mathrm{g} / \mathrm{ml}$ CPT were arrested in the G0/G1 phase significantly (Figure 4A). Furthermore, a significant increase of the sub-G1 population was observed (Figure 4B), confirming that CPT induced dose-dependent apoptosis in these cells $(p<0.01)$. Western blot analysis of cell lysates obtained from HL-60 cells indicated that the CPT-induced arrest in G0/G1 phase was paralleled by the accumulation of p53 and p21 proteins (Figure 4C). 

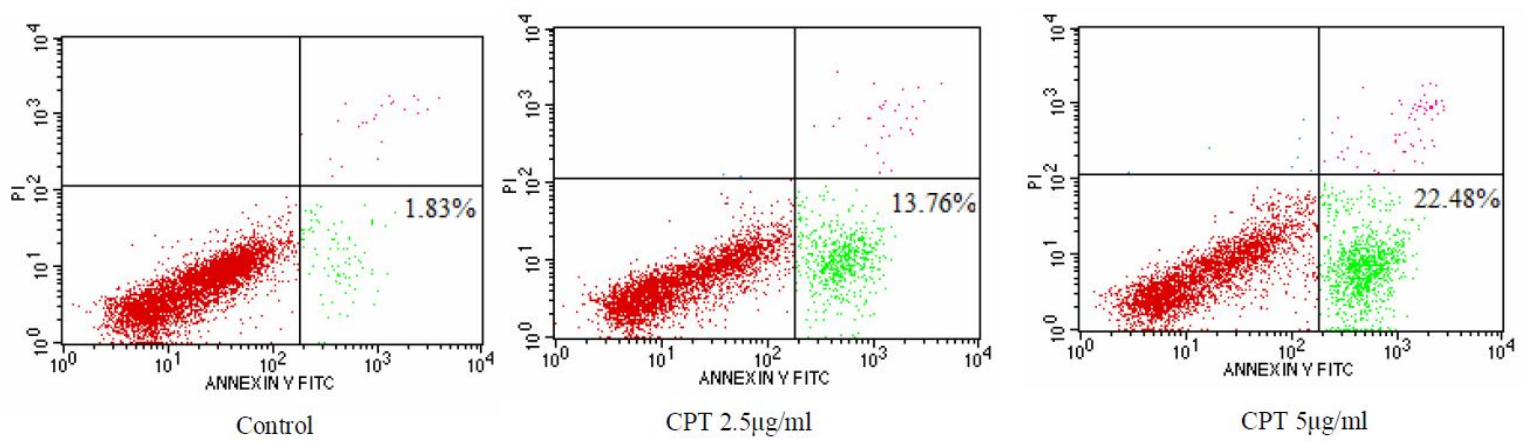

Figure 3: CPT-induced dose-dependent apoptosis in HL-60 cells $(n=3)$. Cells were treated with CPT $(2.5$ and 5 $\mu \mathrm{g} / \mathrm{ml}$ ) for $24 \mathrm{~h}$, stained with Annexin V/PI, and analyzed by flow cytometry. The number shown here represents $\%$ Annexin $\mathrm{V}$ positive and $\mathrm{PI}$ negative population relative to the total
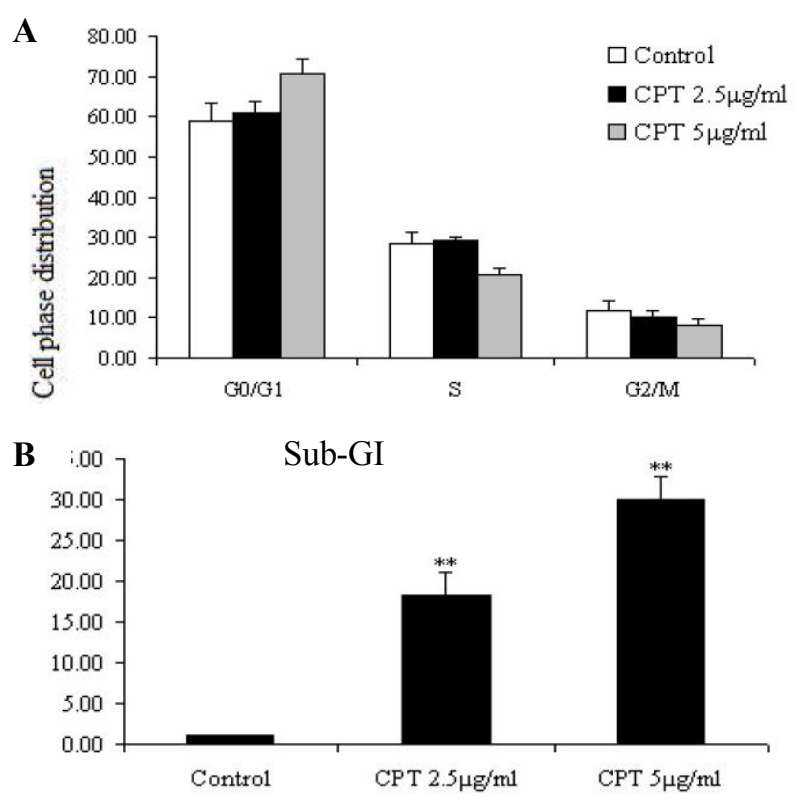

C

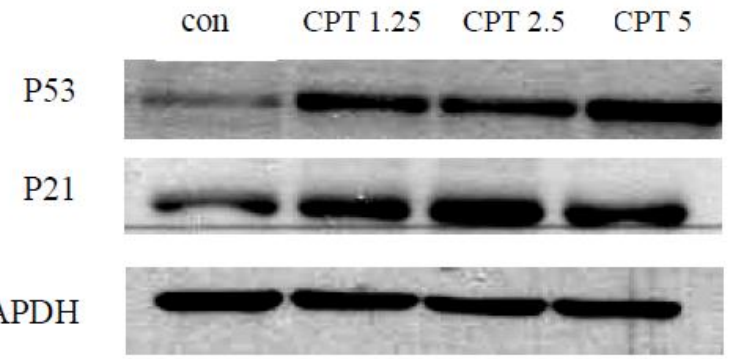

Figure 4: Effect of CPT on cell-cycle phase and apoptosis. HL-60 cells were incubated with CPT $(2.5$ and $5 \mu \mathrm{g} / \mathrm{ml}$ ) for 24 hours (A and B). The cell cycle distribution and induction of apoptosis were analyzed by flow cytometry. $G_{0} / G_{1}, G_{2} / M$, and $S$ indicate cell phase, and sub-G1 refers to the proportion of apoptotic cells. (C) Western blot analysis of cell lysates obtained from HL-60 cells cultured for 24 hours plus CPT. Bands represent immunocomplexes for p53 and $\mathrm{p} 21$. The data shown are representative of three independent experiments; ${ }^{* *} p<0.01$

\section{CPT activated caspase $-3,-8$ and -9 in HL-60}

CPT treatment resulted in a significant increase in caspase- $3,-8$ and -9 activity compared to control group $(p<0.01$, Figure $5 \mathrm{~A})$. The pancaspase inhibitor, zVAD-FMK, and two specific caspase inhibitors, Z-DEVD-FMK for caspase-3 and Z-LEHD-FMK for caspase-9, could partially abrogate CPT-induced cell death in HL-60 cells (Figure 5B). The pan-caspase inhibitor zVADFMK increased cell viability by up to $61 \%$.

CPT gave rise to loss of mitochondrial membrane potential with $\mathrm{Bcl}-2 / \mathrm{Bax}$ ratio change

HL-60 cells showed a dose-dependent loss of mitochondrial membrane potential (MMP) $(p<0.01$, Figure $6 \mathrm{~A})$ after treatment with CPT for 24 hours. At the same time, CPT increased Bax expression and downregulated $\mathrm{Bcl}-2$ activation (Figure 6B), resulting less $\mathrm{Bcl}-2 / \mathrm{Bax}$ ratio. Thus, CPT induced HL-60 apoptosis through the mitochondrial pathway involving Bax activation and $\mathrm{Bcl}-2$ inhibition.

\section{CPT triggered cytochrome c release and PARP cleavage}

HL-60 cells treated with CPT were also found to have increasing levels of cytochrome $c$ in the cytosol in a dose-dependent manner (Figure 7). In mitochondria pathway, PARP cleavage is subsequent to casepase-3 activation after casepase- 9 activation by cytochrome $c$ release. Thus, in our study, additional evidence of caspase-3 activation was the cleavage of PARP as investigated by Western blot analysis (Figure 7).

\section{DISCUSSION}

CPT is a natural compound with potential anticancer effect. Recent studies have shown that CPT inhibited proliferation and induced 

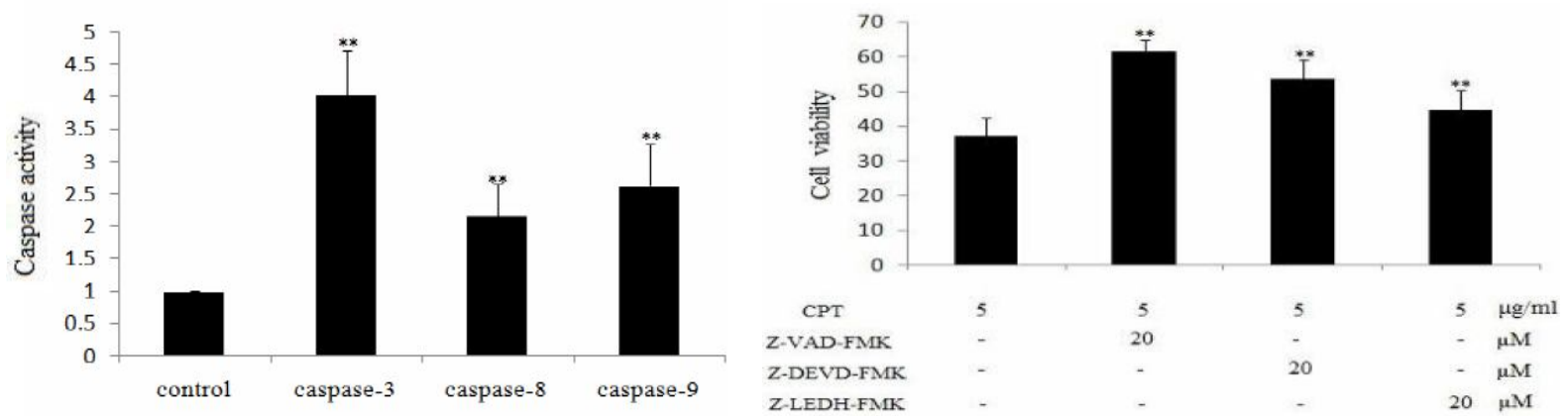

Figure 5: (A) CPT-activated caspase-like enzymes. HL-60 cells were incubated with $5 \mu \mathrm{g} / \mathrm{ml} \mathrm{CPT}$ for $12 \mathrm{~h}$. The cytosol was analyzed for caspase-3, caspase-8, and caspase- 9 activity. (B) Inhibition of CPT-mediated cell death by caspase inhibitors. HL-60 cells were pretreated with or without pan-caspase inhibitor, caspase- 3 inhibitor, and caspase- 9 inhibitor for $12 \mathrm{~h}$, and exposed to CPT for another 48 hours. Columns are representative of the mean $(n=3)$; error bars $=S D ;{ }^{* *} p<0.01$
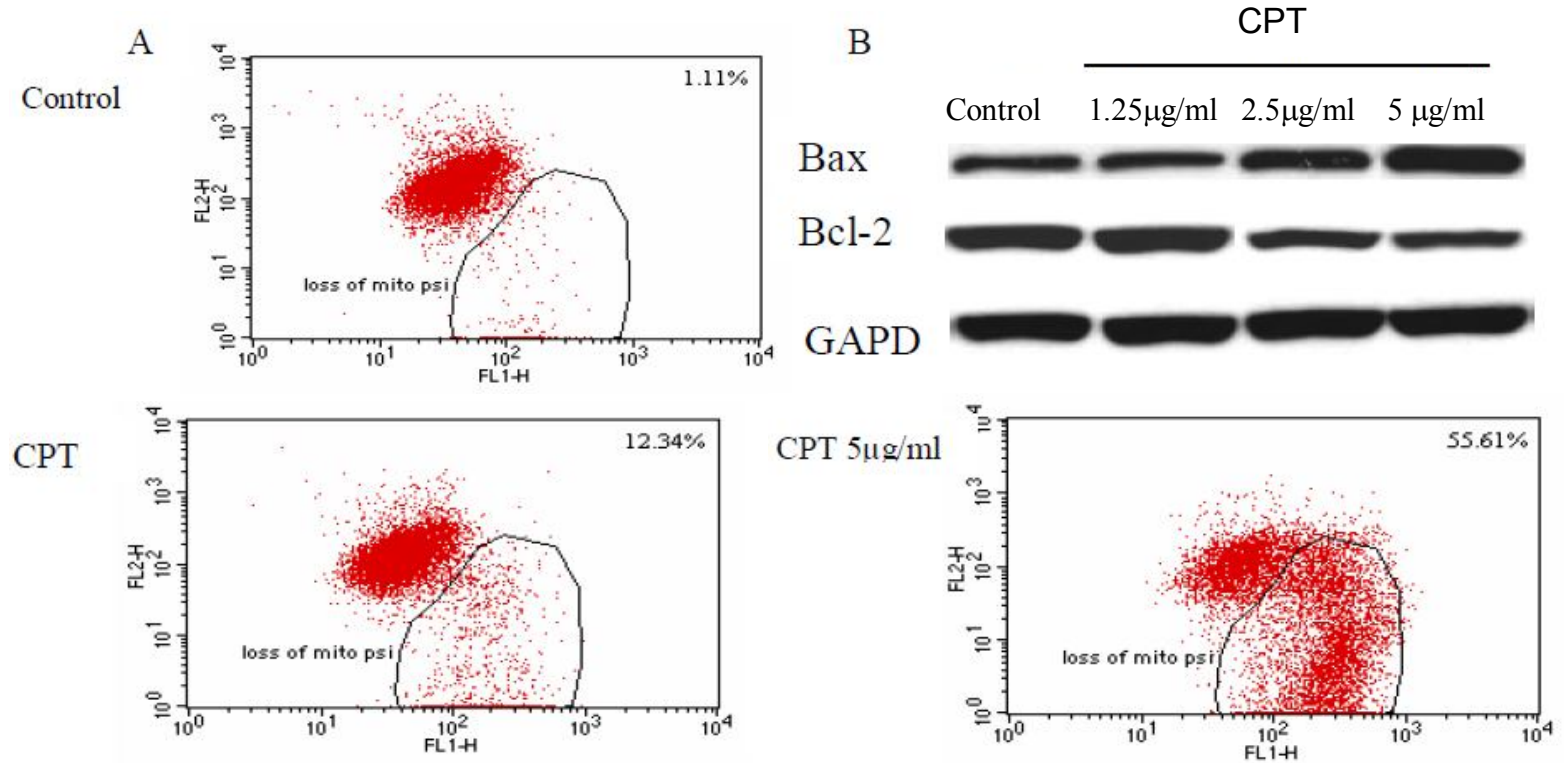

Figure 6: Effect of CPT on mitochondrial membrane potential and Bax/Bcl-2 expression. (A) HL-60 cells were incubated with CPT $(2.5$ and $5 \mu \mathrm{g} / \mathrm{ml}$ ) for $24 \mathrm{~h}$, then assayed for MMP by flow cytometry. CPT triggered a dosedependent disruption of MMP. (B) The lysates of treated cells were analyzed by Western blot. Antibodies to Bax and $\mathrm{Bcl}-2$ were used to detect Bax/Bcl-2 expression in HL-60 cells. CPT increased Bax protein expression in a concentration-dependent manner, while downregulating Bcl-2

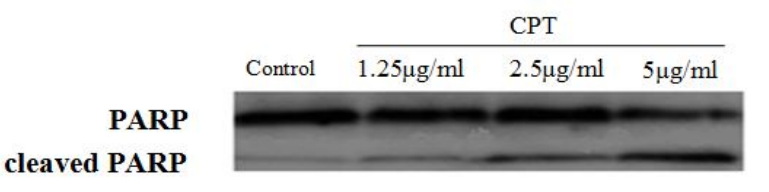

(Cytosolic extract)

Cyt c

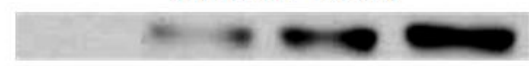

\section{GAPDH}

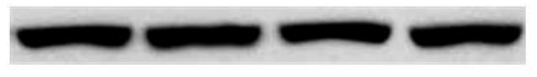

Figure 7: Dose-dependent cleavage of PARP, cytosolic accumulation of cytochrome c. HL-60 cells were treated with varied concentrations of CPT (1.25, 2.5 and $5 \mu \mathrm{g} / \mathrm{ml}$ ) for $24 \mathrm{~h}$. PARP cleavage and cytochrome c activity was detected by Western blot analysis apoptosis of rhabdomyosarcoma cells (Rh30), prostate cancer cells (DU145), breast cancer cells (MCF-7) and hepatocellular carcinoma cells (Hep G2) $[5,7,8]$. The mechanisms involved are arresting cell cycle in G0/G1 phase, downregulation of cyclin D1 expression, hypophosphorylation of $\mathrm{Rb}$, inhibition of STAT3, endoplasmic reticulum stress and et al. However, there is lack of reports on leukemia cells. In this study, we demonstrated that HL-60 cells, a Human promyelocytic leukemia cell line, undergo apoptosis when treated with varying concentrations of CPT. In the MTT assay, CPT showed significant growth inhibition of HL-60 cells. Further investigation showed that CPT exhibited both dose-dependent and timedependent inhibition of cell proliferation in HL-60 cells, by causing G0/G1 arrest. Cell cycle arrest 
in CPT-treated cells was accompanied by a marked increase in the level of sub-G1 phase cells, which reflects the proportion of apoptotic cells (Figures 1, 4). Moreover, the study also demonstrated CPT induced the accumulation of p53 and p21, indicating p53 and p21 proteins activate the transcription of genes encoding for factors involved in G1 to S-phase transition.

Apoptosis is a programmed, essential process of cell death that allows for the removal of damaged cells in order to maintain tissue homeostasis. Classical apoptosis can be mediated by two pathways: the mitochondrial (intrinsic) pathway and the death receptor (extrinsic) pathway $[9,10]$. The mitochondrial pathway is controlled by members of Bcl-2 family proteins comprising both pro-apoptotic proteins (Bax, Bak, and Bid) and anti-apoptotic proteins (Bcl-2 and $\mathrm{Bcl}-\mathrm{xL}$ ) $[11,12]$. The balance between pro- and antiapoptotic proteins determines the fate of cells [13], which is always followed by the loss of MMP, release of cytochrome C [14], and activation of caspase [15]. In our study, the expression of Bax proteins were upregulated and levels of $\mathrm{Bcl}-2$ proteins were downregulated by CPT treatment in a dose-dependent manner. It suggested that decrease of $\mathrm{Bcl}-2 / \mathrm{Bax}$ play important role in apoptosis of HL-60 cells induced by CPT.

Mitochondria acts as a point of integration for apoptotic signals, as both intrinsic and extrinsic pathways trigger the disruption of mitochondrial membrane permeability. Our data demonstrated that CPT treatment leads to a dose-dependent collapse of MMP, which was subsequent to Bcl2/Bax decrease.

Cytochrome $\mathrm{c}$ is a key factor which is released from the mitochondria into the cytosol during apoptosis [16]. When mitochondria membrane permeability increases after loss of MMP, cytochrome c releases from mitochondria, which leads to caspase-9 activation, which subsequently activates caspase-3 [17]. Here, we demonstrated that $\mathrm{CPT}$ induced the release of cytochrome $\mathrm{c}$ from the mitochondria to the cytosol in HL-60 cells in a time-dependent manner. These results suggest that CPT induces HL-60 apoptosis through a mitochondrialdependent pathway.

Both extrinsic and intrinsic pathways are regulated by caspases, which are responsible for cascade activation during apoptosis, induced by many stimuli [18]. Activation of caspase initiators (procaspases 8-10) leads to proteolytic activation of downstream effector caspases (caspase-3, -6, -7). In our study, CPT increased the activity of caspase-3, -8, and -9 in a time-dependent manner, and pretreatment with pan-caspase inhibitors or casepase-3, -9 specific inhibitors could partially have prevented CPT-induced HL60 cell death (Figure 5). Therefore, casepase-3, 8 and -9 was important executor in apoptosis of HL-60 cells induced by CPT.

\section{CONCLUSION}

It has been demonstrated in this study that CPT effectively induces apoptosis of HL-60 cells, which starts with decrease of $\mathrm{Bcl}-2 / \mathrm{Bax}$ ratio, followed by loss of MMP, release of cytochrome C, activation of caspase-3, -8 , and -9 , cleavage of PARP. Meanwhile, arrest of G0/G1 phase occurs due to accumulation of p53 and p21. These findings suggest CPT might be a potential therapeutic and chemopreventive agent for leukemia, but further in vitro and in vivo experiments should be carried out to ascertain this.

\section{ACKNOWLEDGEMENT}

This work was supported by National Natural Science Foundation of China grant no. 81070419 (Wenbin Qian, Wanmao Ni), Zhejiang Provincial Health Department of China grant no. 2011ZDA008 (Xiangmin Tong, Wanmao Ni) and Zhejiang Provincial Health Department of China grant no. 2012RCA017 (Wanmao Ni).

\section{REFERENCES}

1. Appelbaum FR, Rowe JM, Radich J, Dick JE. Acute myeloid leukemia. Hematology Am Soc Hematol Educ Program. 2001; 62-86.

2. Mason KD, Juneja SK, Szer J. The immunophenotype of acute myeloid leukemia: is there a relationship with prognosis? Blood Rev. 2006; 20: 71-82.

3. Ravandi F, Burnett AK, Agura ED, Kantarjian HM. Progress in the treatment of acute myeloid leukemia. Cancer. 2007; 110: 1900-1910.

4. Jin DZ, Yin LL, Ji XQ, Zhu XZ. Cryptotanshinone inhibits cyclooxygenase-2 enzyme activity but not its expression. Eur J Pharmacol. 2006; 549: 166-172.

5. Chen W, Luo Y, Liu L, Zhou H, Xu B, Han X, Shen T, Liu Z, Lu Y, Huang S. Cryptotanshinone inhibits cancer cell proliferation by suppressing Mammalian target of rapamycin-mediated cyclin $D 1$ expression and $R b$ phosphorylation. Cancer Prev Res (Phila). 2010; 3: 1015-1025.

6. Lee WY, Chiu LC, Yeung JH. Cytotoxicity of major tanshinones isolated from Danshen (Salvia miltiorrhiza) on HepG2 cells in relation to glutathione perturbation. Food Chem Toxicol. 2008; 46: 328-338. 
7. Shin DS, Kim HN, Shin KD, Yoon YJ, Kim SJ, Han DC, Kwon BM. Cryptotanshinone inhibits constitutive signal transducer and activator of transcription 3 function through blocking the dimerization in DU145 prostate cancer cells. Cancer Res. 2009; 69: 193202.

8. Park IJ, Kim MJ, Park OJ, Choe W, Kang I, Kim SS, Ha J. Cryptotanshinone induces ER stress-mediated apoptosis in HepG2 and MCF7 cells. Apoptosis. 2012; 17: 248-257.

9. Criollo A, Galluzzi L, Maiuri MC, Tasdemir E, Lavandero $S$, Kroemer G. Mitochondrial control of cell death induced by hyperosmotic stress. Apoptosis. 2007; 12: 3-18.

10. Wajant $H$. The Fas signaling pathway: more than a paradigm. Science. 2002; 296: 1635-1636.

11. Allen RT, Cluck MW, Agrawal DK. Mechanisms controlling cellular suicide: role of $\mathrm{Bcl}-2$ and caspases. Cell Mol Life Sci. 1998; 54: 427-445.

12. Cory S, Adams JM. The Bcl2 family: regulators of the cellular life-or-death switch. Nat Rev Cancer. 2002; 2: 647-656.

13. Perskvist N, Long M, Stendahl O, Zheng $L$. Mycobacterium tuberculosis promotes apoptosis in human neutrophils by activating caspase-3 and altering expression of $\mathrm{Bax} / \mathrm{BCl}-\mathrm{xL}$ via an oxygendependent pathway. J Immunol. 2002; 168: 63586365.

14. Kuwana T, Newmeyer $D D$. Bcl-2-family proteins and the role of mitochondria in apoptosis. Curr Opin Cell Biol. 2003; 15: 691-699.

15. Mueller $T$, Voigt $W$, Simon $H$, Fruehauf $A$, Bulankin $A$, Grothey A, Schmoll HJ. Failure of activation of caspase-9 induces a higher threshold for apoptosis and cisplatin resistance in testicular cancer. Cancer Res. 2003; 63: 513-521.

16. Banjerdpongchai $R$, Kongtawelert $P$, Khantamat $O$, Srisomsap C, Chokchaichamnankit D, Subhasitanont $P$, Svasti J. Mitochondrial and endoplasmic reticulum stress pathways cooperate in zearalenone-induced apoptosis of human leukemic cells. J Hematol Oncol. 2010; 3: 50.

17. Li P, Nijhawan D, Budihardjo I, Srinivasula SM, Ahmad $M$, Alnemri ES, Wang X. Cytochrome $c$ and dATPdependent formation of Apaf-1/caspase-9 complex initiates an apoptotic protease cascade. Cell. 1997; 91: 479-489.

18. Grütter MG. Caspases: key players in programmed cell death. Curr Opin Struct Biol. 2000; 10: 649-655. 